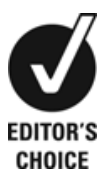

CHOICE

\title{
Wearable technology: using Google Glass as a teaching tool
}

\author{
Hui Min Knight, ${ }^{1}$ Parag Ravindra Gajendragadkar, ${ }^{2}$ Awais Bokhari ${ }^{2}$
}

${ }^{1}$ Department of Medicine, Bedford Hospital, Bedford, UK ${ }^{2}$ Department of Cardiology, Bedford Hospital, Bedford, UK

\section{Correspondence to} Dr Hui Min Knight, hmtan@btinternet.com

Accepted 2 April 2015

\section{SUMMARY}

Wearable technology holds great promise in revolutionising healthcare delivery. The benefits can also be seen in medical education and delivering healthcare in remote places. We report the use of Google Glass technology as a teaching tool in broadcasting a procedure onto a mobile phone as a viewer, replacing expensive and often cumbersome existing equipment.

\section{BACKGROUND}

Broadcasting surgical procedures is often only possible in specially designed theatre environments, using expensive and cumbersome equipment. Having obtained Google Glass technology, we wanted to explore the potential for making medical procedures easily accessible and wondered about how easy it might be to screencast the view from the in-built camera to a smartphone display during a procedure. The ease and clarity with which this was performed was something we felt may have many uses for medical education.

\section{CASE PRESENTATION}

A 20-year-old woman with no medical or family history came to cardiology services with palpitations that were associated with presyncope. She had a normal resting ECG, normal echocardiogram and an initial $24 \mathrm{~h}$ ambulatory ECG monitor showed sinus rhythm. She did not record any symptoms when given a cardiac memo device. After a period of being symptom free, she had further symptomatic palpitations but these settled by the time medical contact was sought.

An implantable loop recorder (ILR) was considered but due to her slim build, she was not keen on the previous generation Reveal DX model (Medtronic). At the time, a newer, smaller and injectable ILR (LINQ, Medtronic) was being made commercially and was widely available; it was felt she would be a good candidate for this, to which she consented.

The LINQ device had not previously been implanted at our institution. The operator (AB) had also recently obtained the new Google Glass (Google Inc) (figure 1A), a wearable set of glasses with in-built camera and heads-up display, which has Internet connectivity. It also has in-built broadcast features via Bluetooth connectivity. As other operators (PRG) showed interest in watching the first LINQ implant, we wondered whether broadcasting the procedure was possible.

After appropriate patient consent, we paired Google Glass with a Samsung Galaxy Note 3 (Samsung) via Bluetooth. $\mathrm{AB}$ wore the Google Glass while performing the procedure in the theatre environment. PRG sat in the control room area remotely viewing on the Samsung phone what the Google Glass wearer was seeing (figure 1B-D).

The procedure was completed successfully and without complications, and the patient was discharged shortly afterwards.
To cite: Knight $\mathrm{HM}$, Gajendragadkar PR, Bokhari A. BMJ Case Rep Published online: [please include Day Month Year] doi:10.1136/bcr-2014208768
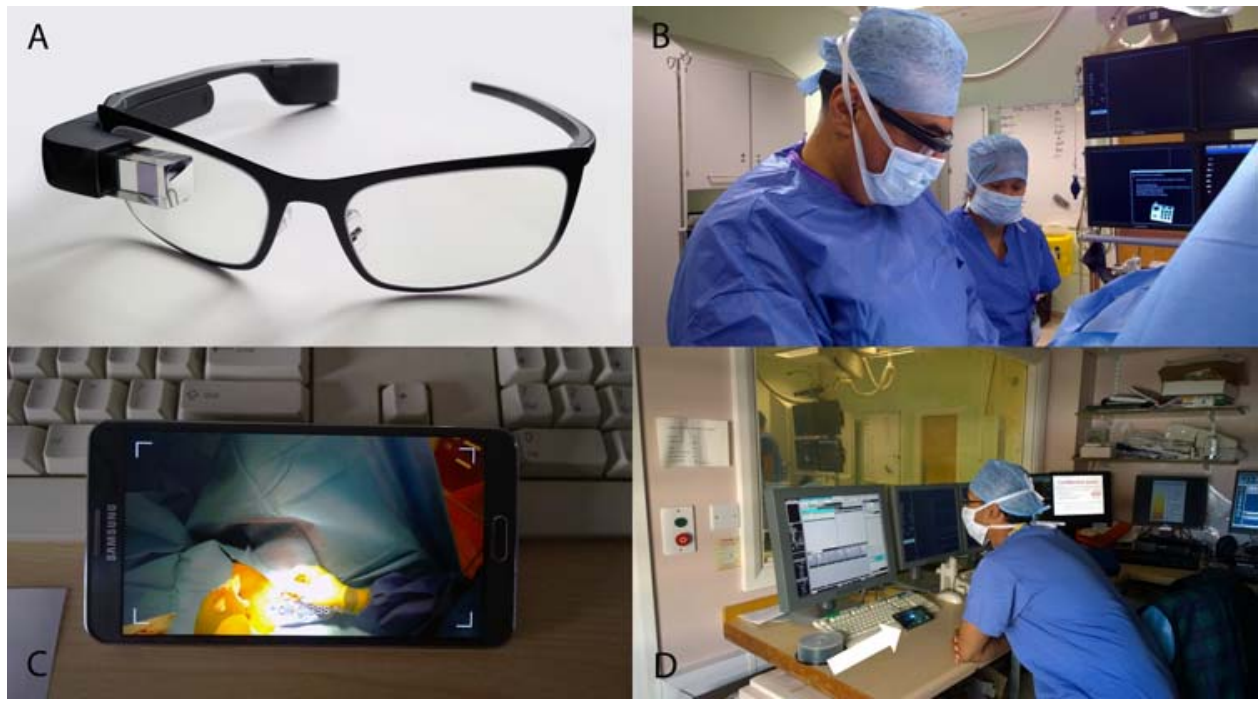

Figure 1 (A) Google Glass; (B) Operator (AB) wearing Google Glass; (C) Samsung Galaxy Note 3 showing screencast of procedure from Google Glass; (D) PRG viewing screencast remotely on Samsung phone (arrowed) in control room. 


\section{OUTCOME AND FOLLOW-UP}

As yet, the patient has had no further symptomatic palpitations.

In the context of medical education, the Google Glass broadcasting of a live procedure over a short distance via Bluetooth appeared to be successful. For the technology to be deemed useful, a number of factors were considered. The ease of use of the technology for the person doing the procedure and the person viewing it were important factors. AB's Google Glass came with prescription lenses so it was unobtrusive and he reported no difficulties in completing the procedure. The pairing process via Bluetooth was simple and PRG reported no difficulties getting set up.

The important consideration was whether watching the procedure using this setup was useful from a training perspective. PRG reported that watching the procedure on the highdefinition screen of the Samsung Note phone was a good experience. Owing to broadcasting over a short distance using Bluetooth, there was no lag reported in the audio/video signal. Additionally, the Google Glass's unique viewpoint from the operator's eyeline was useful to someone who might be training to perform a procedure themselves.

\section{DISCUSSION}

The use of technology to aid medical education is well described. We report another such case in which wearable technology could be used to aid the teaching of procedures without a large amount of expensive equipment (eg, video headsets, transmission wiring and screens). A recent study compared Google Glass and GoPro cameras in the field of plastic surgery. ${ }^{1}$ The authors concluded that Google Glass would be a good way for trainees to easily acquire intraoperative footage for selfreview whereas the more cumbersome GoPro would be used to amass a video library of common operations. A recent press release from the University of California, Irvine (UCI) has suggested that Google Glass may be integrated into its medical teaching courses for exactly such reasons. ${ }^{2}$

As well as being used by trainers to broadcast to trainees, some case reports have suggested that Google Glass may be used by trainers to instruct trainees wearing Google Glassso-called 'telementoring'. Studies have reported success in orthopaedic shoulder surgery ${ }^{3}$ and in training people to acquire simple views during cardiac ultrasonography. ${ }^{4}$ There are some limitations - a study reported limitations regarding the camera resolution of Google Glass in some scenarios of ECG interpretation. ${ }^{5}$ A study in a simulated disaster environment compared paramedics conducting traditional triage versus triage using Google Glass broadcasting to an off-site physician. ${ }^{6}$ There was no difference in accuracy of triage but Google Glass mediated triage took substantially longer. This highlights the fact that rigorous evaluation of telemedicine is required when considering 'replacement' of established procedures.

There are ethical considerations. A study has shown that live broadcasting does not increase operative risk in cardiac surgery. ${ }^{7}$
However, these findings are not necessarily translatable across all surgical disciplines, surgeons and type of recording equipment. Patient consent is important (which we obtained) but we decided not to store any videodata. There may be issues about safety of such data regarding storage. The General Medical Council (GMC, UK) makes it clear that explicit consent must be obtained $^{8}$ and the Data Protection Act, 1998, also makes it clear that data must be stored appropriately and only for the necessary length of time. As technology becomes more pervasive, physicians, patients and the public need to come to decisions regarding appropriate uses as well as setting boundaries. This is necessarily a dynamic process as the speed of technological development accelerates.

\section{Learning points}

- Applications of wearable technology within medicine are likely to expand as technology advances.

- The use of Google Glass for broadcasting of procedures for others to view appears easy and effective.

- Up-to-date guidance for doctors regarding the use of technology in a safe and ethical manner is needed.

Contributors HMK and PRG wrote the article with $A B$ providing critical review. $P R G$ and $A B$ carried out the procedure and looked after the patient.

Competing interests None declared.

Patient consent Obtained.

Provenance and peer review Not commissioned; externally peer reviewed.

\section{REFERENCES}

1 Paro JAM, Nazareli R, Gurjala A, et al. Video-Based Self-Review: Comparing Google Glass and GoPro Technologies. Ann Plast Surg 2015. Published Online First: 7 February 2015.

2 UCI Press Release, 14 May 2014. http://news.uci.edu/press-releases/ uci-school-of-medicine-first-to-integrate-google-glass-into-curriculum/

3 Lindeque BGP, Ponce BA, Menendez ME, et al. Emerging technology in surgical education: combining real-time augmented reality and wearable computing devices. Orthopedics 2014;37:751-7.

4 Russell PM, Mallin M, Youngquist ST, et al. First 'glass' education: telementored cardiac ultrasonography using Google Glass-a pilot study. Acad Emerg Med Off J Soc Acad Emerg Med 2014;21:1297-9.

5 Jeroudi OM, Christakopoulos G, Christopoulos G, et al. Accuracy of remote electrocardiogram interpretation with the use of google glass technology. Am J Cardiol 2015;115:374-7.

6 Cicero MX, Walsh B, Solad $Y$, et al. Do you see what I see? Insights from using google glass for disaster telemedicine triage. Prehospital Disaster Med 2015;30:4-8.

7 Seeburger J, Diegeler A, Dossche K, et al. Live broadcasting in cardiac surgery does not increase the operative risk. Eur J Cardio-Thorac Surg Off J Eur Assoc Cardio-Thorac Surg 2011;40:367-71.

8 GMC. Making and using visual and audio recordings of patients. April 2011. 
Copyright 2015 BMJ Publishing Group. All rights reserved. For permission to reuse any of this content visit http://group.bmj.com/group/rights-licensing/permissions.

BMJ Case Report Fellows may re-use this article for personal use and teaching without any further permission.

Become a Fellow of BMJ Case Reports today and you can:

- Submit as many cases as you like

- Enjoy fast sympathetic peer review and rapid publication of accepted articles

- Access all the published articles

- Re-use any of the published material for personal use and teaching without further permission

For information on Institutional Fellowships contact consortiasales@bmjgroup.com

Visit casereports.bmj.com for more articles like this and to become a Fellow 